\title{
The Editorial Process
}

\section{AUTHOR GUIDELINES}

PJN is an international peer - reviewed, professional journal for nurses. Welcomes articles on all aspects.The manuscripts will be reviewed for possible publication with the understanding that they are being submitted to one journal at a time and have not been published, simultaneously submitted or already accepted for publicationelsewhere.

The Editors review all submitted manuscripts initially. Manuscripts with insufficient originality, serious scientific and technical flaws or lack of a significant message are rejected. All manuscripts received are duly acknowledged. Manuscripts are sent to two or more expert and international peer reviewers without revealing the identity of the contributors to the reviewers. Each manuscript is also assigned to a member of the editorial team, who based on the comments from the reviewers takes a final decision on the manuscript. The contributors will be informed about the reviewer"s comments and acceptance/ rejection ofmanuscript.

\section{Types of Manuscripts and Limits}

- Original articles: Randomized controlled trials, intervention studies, studies of screening, outcome studies, case-control series, and surveys with high response rate. Up to 3000 words excluding adequate references and abstract.

- Review articles (including for Ethics forum, Education forum, Health related science, EMedicine, E-Nursing etc.): Systemic critical assessments of literature and data sources. Up to 2000 words excluding with adequate references. Research articles critical review, advertisement, functions celebrated, puzzles and innovation relateditems.

- Case reports: new/ interesting/ very rare cases can be reported. Cases with clinical significance or implications will be given priority. However, mere reporting of a rare case may not be considered. Up to 1000 words excluding references and abstract and up to 05 references.

\section{Presentation and Submission of Article}

- Double spacing, TIMES NEW ROMAN

- Margins $2.5 \mathrm{~cm}$ from all foursides

- Title contains all the desiredinformation

- Abstract page contains the full title of themanuscript

- Introduction of 75 words.

- Headings in title case ( not ALLCAPITALS)

- The references cited in the text \& should follow Vancouver both for journals \& look reference.

- Send the final article file without „Track changes" \& send hard \& soft copy for the articles. 


\section{Language and grammar}

- Write the full term for each abbreviation at its first use in the title, abstract, keywords and text separately unless it is a standard unit ofmeasure.

- Numerals at the beginning of the sentence speltout.

- Check the manuscript for spelling, grammar and punctuation errors

Tables and Figures

- No repetition of data in tables and graphs and intext

- Actual numbers from which graphs drawn,provided

- Figures necessary and of good quality (color)

- Table and figure numbers in Arabic letters (notRoman)

- Write the full term for each abbreviation used in the table as afootnote.

Article from Graduate and Post Graduate will also be accepted. Please follow the same format for research articles.

- Title

- Abstract

- Introduction - Objectives/Need for the study withjustification

- Materials and methods-includes Research design, approach, setting, population, sample size \&techniques

- Major Findings with Tables and Figures forobjectives

- References

Author information in a separate page as follows:

- Name, Academic degree,Designation

- Name of theinstitution

- Address for correspondence including phone number and Email Id.

All articles will be peer reviewed. The Editorial board and chief editor will decide on suitabililty of publication of a material which is final. The last minute submission of article will not be considered for current issue.

\section{Correspondence Address:}

Prof. Dr. Renuka K

Chief Editor, Pondicherry Journal of Nursing

Principal, Kasturba Gandhi Nursing College, MGMC\&RI Campus,

Pillaiyarkuppam, Puducherry - 607402.

Ph: 0413-2615449 (Ext.511), 2615809, Fax: 0413-2615457

E-mail-kgncpjn@yahoo.com 